ORIGINAL ARTICLE

\title{
Dissociation between back pain and bone stress reaction as measured by CT scan in young cricket fast bowlers
}

\author{
H B Millson, J Gray, R A Stretch, M I Lambert
}

Br J Sports Med 2004;38:586-591. doi: 10.1136/bjsm.2003.006585

See end of article for authors' affiliations

\section{Correspondence to:}

Helen B Millson, Research Unit for Exercise Science and Sports Medicine, UCT/MRC, PO Box 115 University of Cape Town Newlands 7725, Cape Town, South Africa; helenmil@mweb.co.za

Received 21 August 2003 Accepted for publication 25 August 2003
Background: Bone stress reaction is prevalent among cricket fast bowlers. Few studies have addressed the sensitivity and specificity of imaging for diagnosis, and follow up assessment has been poorly investigated. Objective: To determine whether there was an association between back pain and bone stress reaction as measured by computed tomography (CT) scan in young cricket fast bowlers.

Methods: Ten young cricket fast bowlers were included in the study. Nine bowlers presented to a physiotherapy practice with low back pain and were later diagnosed with lumbar stress fractures, while one was an experienced bowler with no pain. All players had a CT scan after presenting to the physiotherapy practice. Pain was assessed according to a subjective scale (0-10) where 10 represented the player's subjective, maximum pain score. Recovery and rehabilitation of all players was monitored until they returned to full participation.

Results: There was no consistency in the relationship between pain and CT scan results. For example, one subject had evidence of un-united stress fractures after 15 months of rest but had experienced moderate pain for only 2 weeks after the onset of symptoms, in contrast to another subject who had intermittent pain for 11 months even though CT scan showed multiple stress fractures ranging from partially healed to fully healed status at 3 months.

Conclusion: There is dissociation between back pain and bone stress reaction as measured by CT scan. Therefore, CT scan does not provide objective evidence for ongoing management or decision concerning return to sport in cricket fast bowlers. umbar spondylolysis is a common structural defect which affects approximately $4-6 \%$ of the general population..$^{1-4}$

- However, there is an increased incidence of this condition in certain groups of sportsmen and women..$^{5-7}$ In particular, young athletes involved in sports that require hyperextension of the spine, especially if this movement is combined with rotation and side flexion, are at high risk for spondylolysis. ${ }^{8} 9$ Fast bowling in cricket is an example of a sport which involves this combination of movements. ${ }^{410-16}$ Pars interarticularis abnormalities occur in $11-60 \%$ of the cricket population. $^{7111718}$

Fast bowlers with pars interarticularis defects do not always have associated lower back pain. In one study, 11 out of $20(55 \%)$ young fast bowlers had pars interarticularis defects. ${ }^{6}$ Nine of these bowlers $(82 \%)$ with pars interarticularis defects had pain induced by bowling and two (18\%) were asymptomatic. ${ }^{6}$ Another study has shown that spondylolysis is commonly asymptomatic or may be associated with low back pain from other causes. ${ }^{4}$ Furthermore, a study in which young fast bowlers were investigated over 2.7 years showed an inconsistent relationship between disc degeneration and back pain. ${ }^{19}$

As a result of these phenomena fast bowlers presenting with back pain provide the clinician with several challenges. Firstly, there is difficulty differentiating symptomatic spondylolysis, for example the acute/subacute stress fracture, from asymptomatic chronic spondylolysis. Secondly, the anatomical origin of the lower back pain can be difficult to determine. Thirdly, there are no well investigated, clearly articulated objective criteria for a diagnosis of clinically relevant bone stress. Therefore, clinicians are often in a quandary as to when the fast bowler may return to full participation in bowling, particularly as symptoms of pain may or may not be associated with the condition. Various radiological investigations are currently used in the evaluation of bone stress status (plain radiography, computed tomography (CT), isotope bone scan, planar bone scintigraphy, single photon emission computed tomography, and magnetic resonance imaging (MRI).$^{40}$ However, none of these diagnostic procedures have been studied prospectively with particular reference to pain in cricket fast bowlers. Therefore the aim of this study was to determine if there was an association between lower back pain and bone stress reaction as measured by CT scan in young cricket fast bowlers.

\section{METHODS}

The design of this study is a series of case studies. The study was granted clearance by the Ethics and Research Committee of the University of Cape Town. Nine young cricket bowlers who presented to a physiotherapy practice with low back pain and were diagnosed with stress fractures in their lumbar spines were included in this study. One experienced bowler without back pain was also included in the study. The clinical diagnosis was made based on subjective and objective clinical assessment. The final diagnosis was made based on a combination of radiological interventions. All subjects gave written consent to participate in the study.

The imaging protocol was as follows. When the patient presented with low back pain, a plain $x$ ray of the lumbar spine was taken to determine the presence or absence of spondylolysis or chronic stress injury of the pars interarticularis in the lumbar vertebra and to screen for other pathological conditions. Anterior-posterior, lateral, flexion, and extension stress views and two oblique views were taken. Next, a radionuclide scan was performed. This identified any hot spot (that is, increased turnover of bony matrix) and, if one was present, allowed the CT scan to be localised to a

Abbreviations: $\mathrm{CT}$, computed tomography; MRI, magnetic resonance imaging 

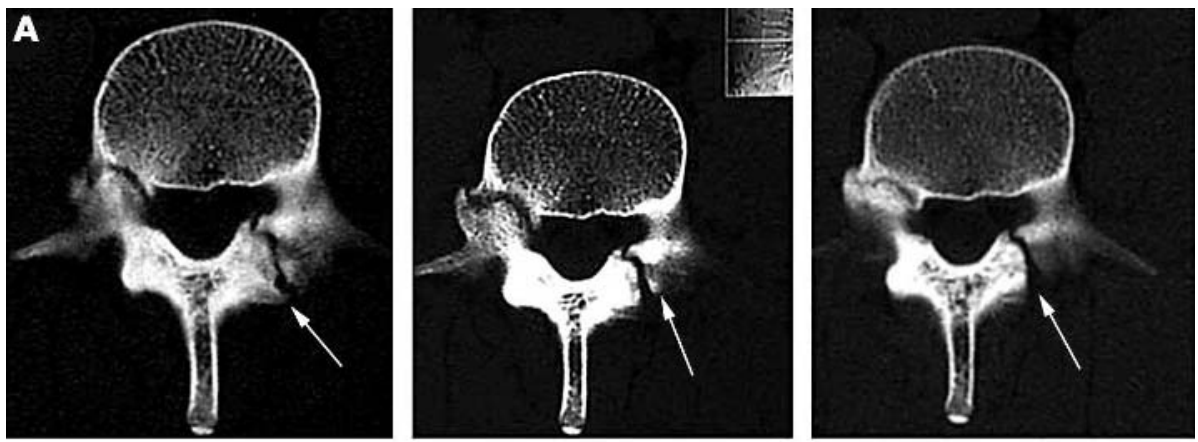

Figure 1 CT scan in a 17 year old right arm bowler (subject 1) which shows (A) non-bony union of the left pars interarticularis of the 4 th lumber vertebra, 6, 8, and 15 months after the original symptoms, and (B) a partially united fracture of the right pedicle of the 4 th lumbar vertebra after 6,8 , and 15 months.

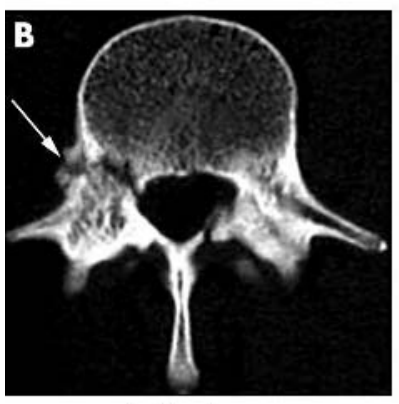

6 Months

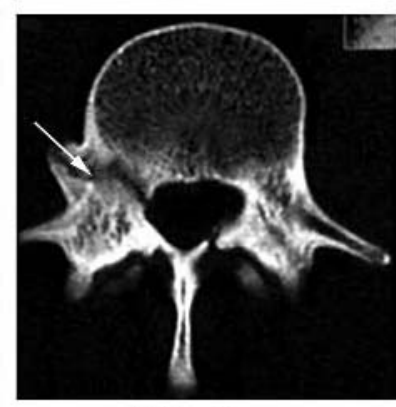

8 Months

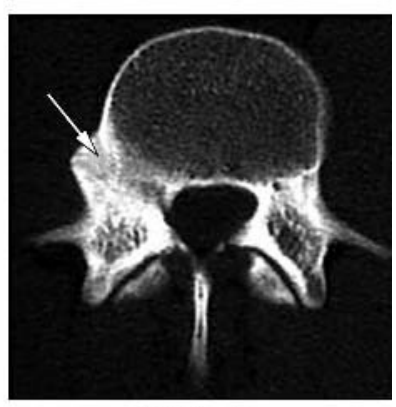

15 Months specific level or levels of recent injury to see if there was a linear defect in the bone or simply a sclerotic reaction.

\section{CT scan protocol}

Scan factors were optimised to reduce radiation levels, without compromising diagnostic quality. The following procedure was undertaken: $3 \mathrm{~mm}$ thick slices, spiral at 2:1 pitch, $1.5 \mathrm{~s}$ cycle and $146 \mathrm{~mA}(219 \mathrm{~mA}$ total), $140 \mathrm{~V}$. This gives an approximate radiation dose to local tissues of $9 \mathrm{mGy}$ in a normal sized patient as calculated for the Plus 4 Siemans Spiral CT Scanner (Erlangen, Germany). Acceptable dose limits to localised musculo-skeletal tissues in patients are $1 /$ 10 those of radiation workers which would be $1 / 10$ of $300 \mathrm{mGy} / \mathrm{year}$, that is, $30 \mathrm{mGy} / \mathrm{year}$. Therefore, three scans of approximately $9 \mathrm{mGy}$ over a 12 month period would result in radiation of $27 \mathrm{mGy}$ which would be within acceptable annual limits. ${ }^{21}$

The scan position was modified from the normal axial orientation used for disc lesions. The so called reverse gantry angle CT was used. This attempted to scan in plane to visualise the posterior elements of the bony ring of the injured vertebra. This ensured that the scan plane was perpendicular to the fracture and was able to detect a pars interarticularis defect. ${ }^{22}$

Pain experienced during the activities of daily living was assessed according to a verbal analogue scale whereby $0 / 10$ represented no pain and 10/10 was the player's subjective maximum debilitating pain score. Players were also questioned about specific movements which were associated with pain which were scored with the same scale.

\section{RESULTS}

The case reports for each of the 10 subjects are presented.

\section{Subject 1}

A 17 year old right arm fast bowler had low back pain which he scored at 4/10 with hyperextension and sudden movements for 2 weeks. He had mild $(1 / 10)$ pain whenever resuming bowling over the following 6 months. A diagnosis was performed with an $x$ ray, an isotope scan, and a CT scan 6 months after the first symptoms of pain. A CT scan was

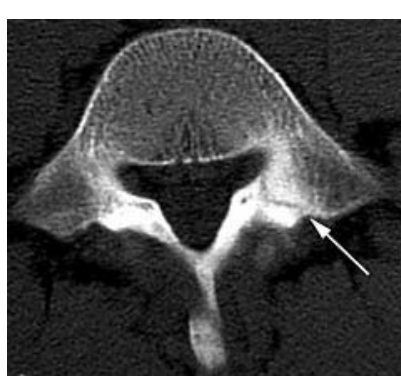

Figure 2 CT scan of subject 2 (15 year old right handed bowler) taken 3 months after the initial presentation of symptoms showing partial healing of the left pars interarticularis stress fracture of the 5th lumbar vertebra. The subject was free of pain 3 weeks after presentation of symptoms.

undertaken again at 2 months after the first CT scan and then again 7 months later. During this time he was advised to stop bowling and experienced no pain at rest. The stress fracture of the left pars interarticularis of the 4th lumbar vertebra remained un-united 15 months after the first symptoms of pain (fig 1A). The fractured right pedicle was partially united after 15 months (fig $1 \mathrm{~B}$ ). During inactivity from cricket, he participated in an intensive rehabilitation programme and returned to full participation after 15 months. He had ongoing assessments for this condition for a further 3 months and experienced no back pain while bowling.

\section{Subject 2}

This 15 year old right arm bowler had mild pain (3/10) for 3 weeks after presenting with his initial symptoms. Further, he had no positive subjective or objective clinical findings and had full range of movement. An $x$ ray and an isotope bone scan were performed when he presented with his symptoms. The $x$ ray showed no abnormal findings, while the isotope bone scan showed an increased area of uptake over the left pars interarticularis of the 5 th lumbar vertebra. This was diagnosed as a stress fracture of the left pars interarticularis of the 5th lumbar vertebra. A CT scan was undertaken at 3 months after the initial presentation of symptoms and showed partial healing of the left pars interarticularis (fig 2). He did not bowl for 6 months after presentation of his first 

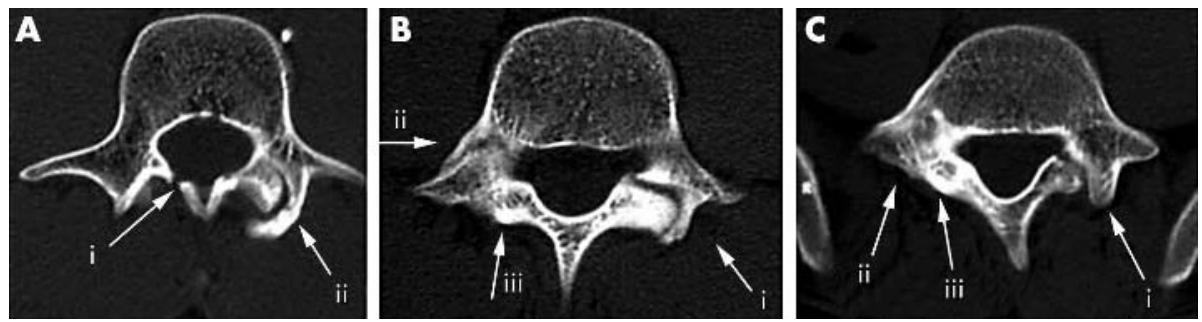

Figure $3 \mathrm{CT}$ scan of a 22 year old right arm bowler (subject 3) of national ranking showing: (A) (i) pseudo-arthrosis of the left pars interarticularis and (ii) un-united lamina fracture of lumbar 3; (B) (i) pseudo-arthrosis of the left pars interarticularis of the 4th lumbar vertebra with a partially un-united fracture through the exostosis, (ii) partial union of the right pedicle, and (iii) union of the right pars interarticularis; and (C) (i) left spondylolysis which showed a subtle area of cross trabeculation in the mid-third of the fracture line, with signs of non-bony union superior and inferior to the area of union. There is a similar bony exostosis, namely a pseudo-arthrosis, and a slight distortion of the spinal canal at this level, (ii) thickening of the right pars interarticularis, and (iii) a thickened, healed fracture of the right pedicle.

symptoms, during which time he underwent an intensive rehabilitation programme. Thereafter he resumed bowling with no further symptoms.

\section{Subject 3}

This 22 year old right arm bowler of national ranking presented with mild low back pain (3/10). He had no previous history of lower back pain or inability to play cricket at any stage during his career. The mild pain of his left lumbar spine was present for 1 week. This pain was present only when overpressure was applied in lumbar extension.

He had an $x$ ray, an isotope bone scan, and a CT scan of the injury on presentation to the physiotherapy practice with this mild back pain. The CT scan showed multiple partially healed and associated areas of un-united fractures of the right and left pars interarticularis and pedicles of the lumbar vertebrae of L3, L4, and L5 (fig 3A, B, and C). Specifically, the CT scan showed a pseudo-arthrosis of the left pars interarticularis of the 3rd lumbar vertebra, and a pseudo-arthrosis of the left pars interarticularis of the 4th lumbar vertebra. There was also a partially healed fracture line through the exostosis. There was a non-union at the right pars of L3, partial union of the right pedicle of L4, and union of the right pars of L4. There was evidence of a healed fracture through the right pedicle with bony cortical and tubercular thickening of the 5 th lumbar vertebra. The left spondylolysis showed a subtle area of cross trabeculation in the mid-third of the fracture line, with signs of non-bony union superior and inferior to the area of union. There was a similar bony exostosis, namely a pseudo-arthrosis. There was a slight distortion of the spinal canal at this level. The subject had no neurological signs at this stage. After the discovery of the stress fracture he did not play cricket for 3 months, during which time he was involved in an intensive rehabilitation programme. Then 2 months after resuming bowling, he developed a stress fracture of his 2nd metatarsal bone of his right foot. He rested for a further 2.5 months before returning to full participation in bowling, but 1 year later sustained a stress fracture of his right mid-femur.

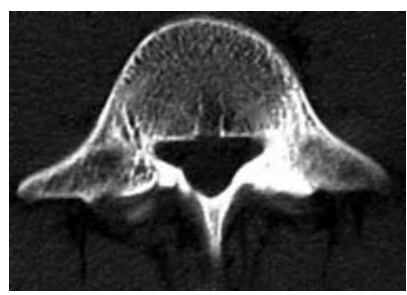

Figure 4 CT scan of an 18 year old right arm bowler (subject 4) showing a healed left pars interarticularis fracture and a partially healed right

interarticularis fracture of the 4 th lumbar vertebra.

\section{Subject 4}

This 18 year old right arm bowler complained of left sided lower back pain (3/10). This cricketer had experienced intermittent pain associated with bowling activity for 11 months after the first symptoms. He only resumed bowling after the 11 month period once he was pain free. The CT scan, taken 3 months after the subject first presented with symptoms, showed a partially healed stress fracture of the right pars interarticularis, and a healed fracture of the left pars interarticularis of the 4th lumbar vertebra (fig 4).

\section{Subject 5}

This 21 year old right arm bowler experienced pain during the bowling delivery. The pain (4/10) was still present 2 weeks after the initial symptoms. He was originally assessed with an $x$ ray and isotope bone scan and diagnosed as having a left pars interarticularis stress fracture of the 5th lumbar vertebra. The CT scan taken 3 months after the original diagnosis made with the isotope bone scan, showed that he had a thickening of the left pars interarticularis and left pedicle, but no stress fracture (fig 5). Based on the original diagnosis of a stress fracture, he did not play cricket for 3 months. His pain was $0 / 10$ after the initial 2 weeks and he remained asymptomatic when he resumed bowling.

\section{Subject 6}

This 15 year old right arm bowler experienced pain (5/10) for 2 weeks after the initial symptoms if he extended his lumbar spine, or stood in a sustained position for a long period. He was initially assessed with an $x$ ray and isotope bone scan and diagnosed as having a left pedicle stress fracture of the 5 th lumbar vertebra. He was advised to avoid cricket for 6 months. A CT scan taken 3 months after the diagnosis showed a thickening of the left pars interarticularis and left pedicle, with no stress fracture (fig 6). He was reassessed after the 6 month period and having no symptoms of pain, returned to bowling with no further problems.

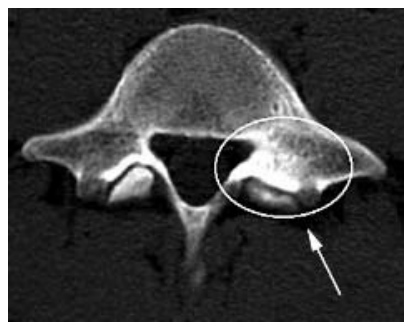

Figure $5 \mathrm{CT}$ scan of a 21 year old right arm bowler (subject 5) at 3 months after presentation showing a thickening of the left pars interarticularis and left pedicle with no stress fracture. The bowler was originally diagnosed with an isotope bone scan as having a left pars interarticularis fracture of 5th lumbar vertebra. 


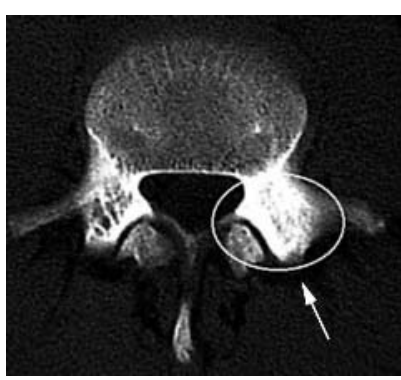

Figure 6 CT scan of a 15 year old right arm bowler (subject 6) taken at 3 months after the diagnosis of a stress fracture (isotope bone scan). This showed a thickening of the left pars interarticularis and left pedicle with no stress fracture.

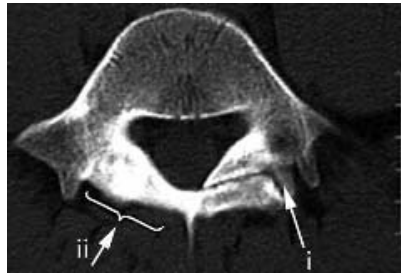

Figure 8 CT scan of a 22 year old right bowler of national ranking (subject 8 ) showing (i) non-union of the left pars interarticularis fracture and (ii) a bony thickening of an old fracture of the right pars interarticularis of the 5 th lumbar vertebra. There is also thickening of the right pedicle of the 5th lumbar vertebra. He did not miss any matches due to back pain during his national career.

\section{Subject 7}

This 21 year old right arm bowler experienced pain (5/10) for 2 weeks after the original symptoms. This pain was only experienced with fast bowling, or after prolonged sitting. He had an $x$ ray followed by an isotope bone scan on first presentation of these symptoms and was diagnosed with increased uptake postero-laterally of the 3rd lumbar spine compatible with a stress fracture. He had been advised to rest from cricket activities for 3 months. The CT scan, taken 2 years after the original diagnosis, showed a thickened healed stress fracture of the left pars interarticularis and a thickened left pedicle (fig 7). During the period following the 3 month rest from cricket activities and the subsequent CT scan, he had bowled with no further back symptoms.

\section{Subject 8}

This 22 year old right arm bowler of national ranking experienced no back pain $(0 / 10)$ at the time of the study, but had experienced some mild back pain during the previous 3 years. He had not had these symptoms of lower back pain investigated. Although he did not miss any matches due to back problems, he agreed to have a CT scan for the study. The scan showed an un-united left pars interarticularis stress fracture of the 5th lumbar vertebra, an un-united right pars fracture of the same vertebra, and right pedicle thickening of the 5th lumbar vertebra (fig 8).

\section{Subject 9}

This 19 year old left arm bowler experienced mild to moderate pain of the right lumbar spine (4.5/10) for 23 weeks after the first symptoms when sitting for sustained periods or occasionally when waking up in the morning. He had a CT scan 4 months after the first symptoms of pain in his right lumbar spine. The scan showed an old lesion with non-bony union of the left pars interarticularis of the 5th lumbar vertebra. This had been asymptomatic, even when bowling. His symptomatic right side showed a non-bony union of the pars interarticularis of the 5th lumbar vertebra (fig 9). He was advised to avoid playing cricket for 6 months because of the bilateral condition and the potential for a spondylolisthesis. He had an intensive rehabilitation programme during this period. After 6 months he had another CT scan which showed non-bony union. The $x$ ray taken at the same time showed that there was a degree of instability

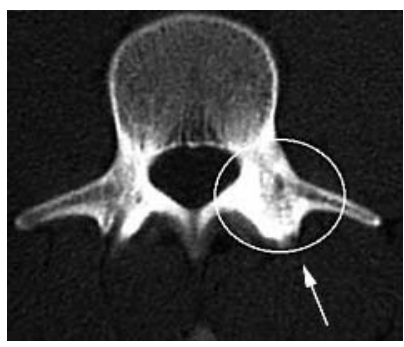

Figure 7 This 21 year old right arm bowler (subject 7) was diagnosed with an isotope bone scan with as having increased uptake in the postero-lateral 3rd lumbar vertebra, compatible with a stress fracture. This CT scan taken 2 years later showed a thickened, healed stress fracture of the left pars interarticularis and a thickened left pedicle. of this vertebra. However, he experienced no further problems when resuming bowling.

\section{Subject 10}

This 17 year old right arm bowler presented with pain in the left lumbar area. The pain was rated as $3 / 10$ and only experienced with extreme lumbar movements and when bowling. This pain lasted for 3 weeks after the initial symptoms. An isotope scan, taken 2 weeks after the original symptoms, showed an increased uptake in the posterior elements of the left L5. The CT scan taken 1 month later (that is, 3 months after the appearance of the symptoms) showed a healing fracture of the left pars interarticularis (fig 10). This cricketer did not play cricket for 3 months after the original symptoms, during which time he underwent an intensive rehabilitation programme. He experienced no further problems once he resumed bowling.

These data are summarised in table 1. The CT scans taken at various stages after injury showed varying degrees of healing of the stress fractures of the posterior elements of the lumbar spine, from non-union to partially healed or fully healed. The status of the fracture did not always correlate with the intensity or duration of pain experienced by the cricketer.

\section{DISCUSSION}

\section{Dissociation between pain and pars defects}

The first important finding of this study was that there was dissociation between pain and spondylolysis or pars interarticularis defect as measured by CT scan. This raises the question of whether pain and/or radiological evidence from a CT scan should be used as a guide for the return of the cricketer to full participation in fast bowling. Both of these factors have been the main points of reference in the clinical setting in the past. It is clear that if pain exists, then the cricketer should not participate in the game or practice. However, based on the findings of this study, there is often no pain or minimal pain, even though there are pars interarticularis defects (with or without union) in the lumbar spine. This was particularly evident in subject 3, who had multiple stress fractures without pain, and subject 8 , who had minimal pain with full bowling participation throughout his career. An interpretation of this observation is that the CT scan may be recording a false positive test, indicating that there is an injury when, in fact, the pain is due to another cause and not the bone stress reaction. The bone stress reaction could be the body's adaptive response to the extraordinary stresses imposed by the biomechanics of fast bowling. An alternative interpretation is that it may be of genetic origin and not relevant to the current lower back pain experienced. The bone isotope scan identified a reaction to a cancellous bone injury, that is, micro fractures of the cancellous bony struts, resulting in oedema and haemorrhage into the cancellous bony spaces. This bone bruising would not be identified on CT scan, unless it had progressed to cortical bone injury. The CT scan is the most sensitive 


\begin{tabular}{|c|c|c|c|c|c|c|}
\hline Subject & Age (years) & Dominant arm & Pain severity and duration & $\begin{array}{l}\text { Time of CT scan (post onset } \\
\text { of injuries) }\end{array}$ & CT diagnosis & Return to fast bowling \\
\hline 1 & 17 & Right & $\begin{array}{l}4 / 10 \text { for } 2 \text { weeks, } 1 / 10 \text { for } \\
6 \text { months }\end{array}$ & $6,8,15$ months & $\begin{array}{l}\text { Partially united and } \\
\text { un-united fractures }\end{array}$ & 15 months \\
\hline 2 & 15 & Right & $3 / 10$ for 3 weeks & 3 months & Partial union & 6 months \\
\hline 3 & 22 & Right & $3 / 10$ for 1 week & Immediately & Multiple partial and & 3 months \\
\hline 4 & 18 & Right & $\begin{array}{l}3 / 10 \text { intermittent with } \\
\text { bowling only }\end{array}$ & 3 months & $\begin{array}{l}\text { Partially healed and healed } \\
\text { fracture }\end{array}$ & 11 months \\
\hline 5 & 21 & Right & $4 / 10$ for 2 weeks & 3 months & Thickening, but no fracture & 3 months \\
\hline 6 & 15 & Right & $5 / 10$ for 2 weeks & 3 months & Thickening, but no fractures & 6 months \\
\hline 7 & 21 & Right & $5 / 10$ for 2 weeks & 2 years & Healed & 3 months \\
\hline 8 & 22 & Right & $0 / 10$ & $\begin{array}{l}\text { Approximately } 3 \text { years after } \\
\text { starting at first class level }\end{array}$ & Un-united fractures & No time off \\
\hline 9 & 19 & Left & $4.5 / 10$ for $2-3$ weeks & 4,6 months & $\begin{array}{l}\text { Bilateral non-union at both } \\
\text { stages }\end{array}$ & 6 months \\
\hline 10 & 17 & Right & $3 / 10$ for 3 weeks & 3 months & Partially healed fracture & 3 months \\
\hline
\end{tabular}

imaging procedure to visualise cortical bone injuries in this area. However, it is insensitive to acute/subacute stress reactions by the bone. Chronic stress reactions may show up as increased sclerosis and thickening of trabeculae. Therefore, the CT scan shows the cortical stress fracture (grade 4), whereas MRI shows the reaction of the trabeculae bone fractures (grade 1-3) indicating bone bruising. ${ }^{43}$ An alternative interpretation could thus be that there is more pain when there is bone bruising (that is, a grade $1-3$ bone stress reaction) and less pain with the cortical stress fracture (grade 4 bone stress reaction). Perhaps if a bone stress reaction is identified at an early stage, a grade 4 stress fracture could be prevented. A clinical concern is that a grade 4 spondylolysis may render the spine anatomically unstable. ${ }^{9}$ Further research needs to be undertaken using MRI as the prime investigation method of choice to identify the stage of bone stress reaction.

\section{Associated bilateral pars defects}

A further finding in this study was that three out of the nine right-handed fast bowlers with a pars stress fracture on the left side showed a non-bony union on this side (subjects 1,3 , $8)$. This was associated with a fractured pedicle on the right side which did heal or partially healed or a fractured pars on the right which did not heal. There was no relationship between whether the fracture was in the pars, the pedicle, or the lamina, and the magnitude and duration of pain.

\section{Clinical relevance for return to bowling}

Another important finding in this study was the relevance of non-bony union (that is, fibrous union) of the stress fracture of the posterior elements of the lumbar spine. This may be interpreted as the body adapting to the extreme ranges of movement required from these spinal joints during the cricket fast bowling action. For example, there was

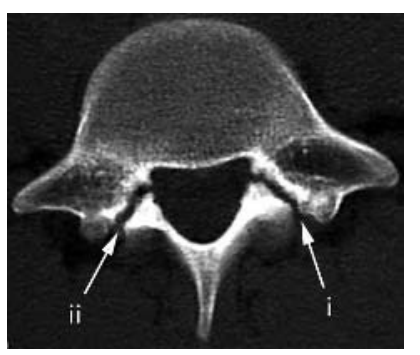

Figure 9 CT scan of a 19 year old left arm bowler (subject 9) taken 4 months after the first symptoms of pain in his lumbar spine. This showed an old lesion with non-bony union of the left pars interarticularis of the 5th lumbar vertebra. The right side shows a non-bony union of the pars interarticularis of the 5th lumbar vertebra. pseudo-joint and osteophyte formation in subject 3. This represents an adaptation of the lumbar spine which may, in fact, be advantageous to the bowler in terms of future mechanical pressure on those structures. This interpretation would, however, depend on the subject observing an intensive specific trunk and pelvic stabilisation programme as excessive spinal joint movement would not be beneficial without adequate muscle control. ${ }^{24}$

Subject 1 was advised to rest from bowling for 15 months based on the continual non-union shown on his CT scan. However, there was no further union after this 15 month rest period. He only experienced pain for 2 weeks after he stopped bowling. The delay in returning to bowling was based on the un-united stress fracture of the left pars interarticularis. The relevance of this clinical decision making needs to be reevaluated. Further research needs to be undertaken to determine whether an earlier return to bowling would be detrimental to the spinal stability of the young fast bowler.

Subject 8 had bowled for a number of years relatively symptom free, unaware of the un-united stress fracture in his lumbar spine. It is reasonable to assume that there may be other players who have been playing symptom free with this condition. This is supported by findings ${ }^{718}$ which showed evidence of stress fractures in asymptomatic fast bowlers. This suggests, certainly in some cases, that un-united stress fractures may have no significant impact on bone health, but may reflect a biological adaptation to bowling.

\section{Genetic predisposition}

Certain studies show that spondylolysis may be familial and that there is an increased incidence in certain families and racial groups. ${ }^{25} \mathrm{~A}$ number of studies show that genetic factors may predispose the individual to spondylolysis. ${ }^{25-27}$ Thus, genetic spondylolysis could be an additional explanation for the stress fractures seen on the CT scan in individuals who

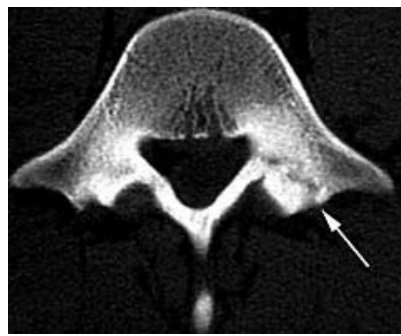

Figure $10 \mathrm{CT}$ scan of this 17 year old right arm bowler (subject 10) shows a healing fracture of the left pars interarticularis of the 5 th lumbar vertebra. 


\section{Take home message}

The significance of spondylolysis and stress fractures of the pars interarticularis in the lower back of the cricket fast bowler remains unclear. Inconsistencies between clinical observations and radiographs have been noted in young fast bowlers with lower back pain. This study showed that there is no relationship between pain and bone stress reaction as measured by $\mathrm{CT}$ scan. An objective assessment measurement is required to advise the fast bowler on return to full participation in fast bowling.

are symptom free. It is important to recognise the age of the fast bowler, training and playing habits, bowling technique, and any postural deficit when managing bone stress injuries of the lumbar spine in cricket fast bowlers. Specifically, this genetic factor may predispose an individual to develop the symptomatic defect, especially when young and playing a high risk sport such as cricket fast bowling. ${ }^{28}$ It is interesting to note that subject 3 developed stress fractures in other regions, which raises the suspicion that he may have had an underlying metabolic disorder which increased his risk of bone stress injury.

\section{CONCLUSION}

This study shows that there is dissociation between pain and bone stress reaction as measured by CT scan. CT scans should only be interpreted in conjunction with findings from a positive isotope or MRI scan and not in isolation. CT scans will have relevance in the acute/subacute setting where there is a proven bone stress reaction on an isotope or MRI scan showing an area of increased bone turnover/metabolism or oedema, respectively. A CT scan may also be used in the follow up of a positively diagnosed injury to assess whether the hot area actually has a fracture, or whether a fracture develops later within the reacting area, and to assess the progression of healing and union of a positively diagnosed acute/subacute fracture. Therefore, the results of a CT scan in isolation from bone isotopes and MRI as an objective method for assessing the management of a player should be used with caution. Furthermore, the results of a CT scan showing a diagnosis of a bone stress fracture do not automatically signify the cause of the pain. There is little research linking the diagnosis of spondylolysis/bone stress reaction of the pars interarticularis of the lumbar spine to pain. Moeller and Rifat state that advanced injuries have a decreased likelihood of complete radiological healing. ${ }^{23}$ Whether this relates to poor outcome such as eventual spondylolisthesis or chronic pain, is not well documented.

However the findings from this study are that there is dissociation between pars and pain.

Following from these case studies many questions arise. For example, in advising the injured fast bowler on return to fast bowling should pain be your guide? Is non-union a problem? What is the clinical relevance of radiological investigations? Further studies are needed to ascertain whether the bone stress reaction is symptomatic or whether the pain is in fact due to other causes.
ACKNOWLEDGEMENTS

Dr Phil Pretorius is thanked for his valuable input on the imaging.

\section{Authors' affiliations}

H B Millson, Research Unit for Exercise Science and Sports Medicine, UCT/MRC, PO Box 115, University of Cape Town, Newlands 7725, Cape Town, South Africa

J Gray, University of Cape Town, Newlands, South Africa

R A Stretch, University of Port Elizabeth, Port Elizabeth, South Africa

M I Lambert, University of Cape Town, Newlands, South Africa

Conflict of interest: none declared.

\section{REFERENCES}

1 Fredrickson B, Baker D, McHolick WJ, et al. The natural history of spondylolisthesis and spondylolysis. J Bone Joint Surg Am 1984:66(5):699-707.

2 McCarrol JR, Miller JM, Ritter MA. Lumbar spondylolysis and spondylolisthesis in college football players. A prospective study. Am J Sports Med 1986; 14:404-6.

3 Hensinger RN, Arbor A. Spondylolysis and spondylolisthesis in children and adolescents. J Bone Joint Surg Am 1989;71(7):1098-107.

4 Harvey CJ, Richenburg JL, Saifuddin A, et al. Pictorial review: the radiological investigation of lumbar spondylolysis. Clin Radiol 1998;53(10):723-8.

5 Ferguson RJ, McMasters MC, Stanitski CL. Low back pain in college school linemen. J Sports Med 1974;2:63-9.

6 Hardcastle $\mathrm{P}$, Annear $\mathrm{P}$, Foster DH, et al. Spinal abnormalities in young fast bowlers. J Bone Joint Surg Br 1992;74:421-5.

7 Annear PT, Chakera TMH, Foster DH, et al. Pars interarticularis stress and disc degeneration in cricket's potent strike force: the fast bowler. Aust N Z J Surg 1992;62(10):768-73.

8 Elliott B, Davis J, Khangure $M$, et al. Disc degeneration and the young fast bowler in cricket. Clin Biomech 1993;8(5):227-34.

9 Hardcastle P. Repair of spondylolysis in young fast bowlers. J Bone Joint Surg $\mathrm{Br}$ 1993;75(3):398-402.

10 Resnick D. Diagnosis of bone and joint disorders. Philadelphia, PA: WB Saunders, 1988:1539-43.

11 Foster D, John D, Elliott B, et al. Back injuries to fast bowlers in cricket: a prospective study. Br J Sports Med 1989;23(3):150-4.

12 Hardcastle P. Lumbar pain in fast bowlers. Aust Fam Physician $1991 ; 20(7): 943,946-51$.

13 Burnett A, Elliot B, Foster D, et al. The back breaks before the wicket: the young bowler's spine. Sport Health 1991;9(4):11-5.

14 Stretch RA. Injuries to South African cricketers playing at first class level. J S Afr Sports Med Assoc 1989;4(1):3-20.

15 Stretch RA. The incidence and nature of injuries in club and provincial cricketers. S Afr Med J 1993;83:339-41.

16 Elliott BC. Back injuries and the fast bowler in cricket. J Sports Sci 2000;18:983-91.

17 Payne WR, Joy G, Carison JS. What research tells the cricket coach. Sports Coach 1987; 10:17-22.

18 Elliott B, Hardcastle P, Burnett B, et al. The influence of fast bowling and physical factors on radiological features in high performance young fast bowlers. J Sports Med Training Rehab 1992;3:113-30.

19 Burnett AF, Khangure MS, Elliott BS, et al. Thoracolumbar disc degeneration in young fast bowlers in cricket: a follow-up study. Clin Biomech 1996; 11:305-10.

20 Anderson I, Read J, Steinweg J. Atlas of imaging in sports medicine. Sydney, Australia: McGraw-Hill, 1998:1-6, 317-20, 355-8.

21 Meredith WJ, Massey B. In: Fundamental physics of radiology. 3rd ed. Bristol, UK: Stonebridge Press, 1977:629-42.

22 Sandrick K. Spinal imaging spots fractures in youth Sports Imaging. 2000; Sept (suppl): 17-9.

23 Moeller JL, Rifat SF. Spondylolysis in active adolescents. Phys Sportsmed 2001;29:27-32.

24 O'Sullivan PB. Lumbar segmental "instability": clinical presentation and specific stabilizing exercise management. Man Ther 2000;5(1):2-12.

25 Saha MM, Bhardwaj OP, Srivastava G, et al. Osteoporosis with spondylolisthesis: 4 cases in 1 family. Br J Radiol 1970;43:738-40.

26 Wiltse LL. The etiology of spondylolisthesis. J Bone Joint Surg 1962:44(3):539-60.

27 Wiltse LL, Widell EH, Jackson DW. Fatigue fracture: the basic lesion in isthmic spondylolisthesis. J Bone Joint Surg Am 1975;57:17-22.

28 Cyron BM, Hutton WC. The fatigue strength of the lumbar neural arch in spondylolysis. J Bone Joint Surg Br 1978;60B(2):234-8. 